\title{
CrystEngComm
}

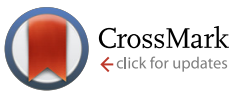

Cite this: CrystEngComm, 2015, 17, 90

Received 26th August 2014, Accepted 1st October 2014

DOI: 10.1039/c4ce01752h

www.rsc.org/crystengcomm

\section{Structural directing roles of isomeric phenylenediacetate ligands in the formation of coordination networks based on flexible $N, N^{\prime}$-di(3-pyridyl)suberoamide $\dagger$}

\author{
Yang-Chih Lo, ${ }^{a}$ Wayne Hsu, ${ }^{a}$ Hsiu-Yi He, ${ }^{a}$ Stephen T. Hyde, ${ }^{* b}$ \\ Davide M. Proserpio*cd and Jhy-Der Chen*a
}

\begin{abstract}
Reactions of the flexible $N_{,} N^{\prime}$-di(3-pyridyl)suberoamide (L) with $\mathrm{Cu}(I)$ salts in the presence of the isomeric phenylenediacetic acids under hydrothermal conditions afforded three new coordination networks, $\left\{[\mathrm{Cu}(\mathrm{L})(1,2-\mathrm{pda})] \cdot \mathrm{H}_{2} \mathrm{O}\right\}_{n}\left(1,2-\mathrm{H}_{2} \mathrm{pda}=1,2-\right.$ phenylenediacetic acid), 1, $\left\{[\mathrm{Cu}(\mathrm{L})(1,3-\mathrm{pda})] \cdot 2 \mathrm{H}_{2} \mathrm{O}\right\}_{n}\left(1,3-\mathrm{H}_{2} \mathrm{pda}=\right.$ 1,3-phenylenediacetic acid), 2, and $\left\{[\mathrm{Cu}(\mathrm{L})(1,4-\mathrm{pda})] \cdot 2 \mathrm{H}_{2} \mathrm{O}\right\}_{n}\left(1,4-\mathrm{H}_{2} \mathrm{pda}=1,4\right.$-phenylenediacetic acid), 3 , which have been structurally characterized by X-ray crystallography. Complex 1 forms a single 3,5-coordinated 3D net with the $\left(4^{2} \cdot 6^{5} \cdot 8^{3}\right)\left(4^{2} \cdot 6\right)-3,5 T 1$ topology, which can be further simplified as a 6 -coordinated $\left(4^{12} \cdot 6^{3}\right)$-pcu topology. Complex 2 is a 5 -fold interpenetrated 3D structure with the $\left(6^{5} \cdot 8\right)$-cds topology, which exhibits the maximum number of interpenetration presently known for cds and complex 3 is the first 1D self-catenated coordination network. The ligand isomerism of the phenylenediacetate ligands is important in determining the structural types of the $\mathrm{Cu}(॥)$ coordination networks based on the flexible $L$ ligands.
\end{abstract}

\section{Introduction}

The design and synthesis of coordination networks with interesting topologies and potential applications have attracted great attention during recent years. ${ }^{1}$ These new complexes thus synthesized are widely applied in catalysis, magnetism materials, gas storage, separation, ion exchange and optics. Entanglement is a very interesting phenomenon in coordination networks, and it is also a major factor contributing to the diversities of coordination networks. ${ }^{2}$

The coordination networks of metal complexes containing flexible bidentate ligands are less predictable due to the possible

\footnotetext{
${ }^{a}$ Department of Chemistry, Chung-Yuan Christian University, Chung-Li, Taiwan, ROC. E-mail:jdchen@cycu.edu.tw

${ }^{b}$ Applied Maths Department, Research School of Physics, Australian National University, Canberra, ACT 0200, Australia. E-mail: stephen.hyde@anu.edu.au ${ }^{c}$ Università degli Studi di Milano, Dipartimento di Chimica, Via Golgi 19, 20133 Milano, Italy. E-mail: davide.proserpio@unimi.it

${ }^{d}$ Samara Center for Theoretical Materials Science (SCTMS), Samara State University, Ac. Pavlov St. 1, Samara 443011, Russia

$\dagger$ Electronic supplementary information (ESI) available: PXRD patterns of 1-3 (Fig. S1-S3). Drawings showing the hydrogen bonds in 2 and 3 (Fig. S4-S5). TGA curves of 1-3 (Fig. S6). Thermal properties of 1-3 (Table S1). CCDC 1014134-1014136. For ESI and crystallographic data in CIF or other electronic format see DOI: 10.1039/c4ce01752h
}

occurrence of supramolecular isomerism involving the adoption of different ligand conformations. ${ }^{3}$ However, the flexible ligands with long spacer lengths are prone to form entangled structures due to their inclination to show large voids. Moreover, the dicarboxylate ligands that show diverse coordination ability can be used as auxiliary building blocks in the construction of coordination networks. ${ }^{4}$ Recently, we have reported two highly interpenetrated diamondoid nets of $\mathrm{Zn}$ (II) and $\mathrm{Cd}(\mathrm{II})$ coordination networks, $\left\{\left[\mathrm{Zn}\left(\mathbf{L}^{\mathbf{1}}\right)(1,4-\mathrm{BDC})\right] \cdot \mathrm{H}_{2} \mathrm{O}\right\}_{n}$ $\left(\mathbf{L}^{1}=N, N^{\prime}\right.$-di(4-pyridyl)adipoamide; $1,4-\mathrm{H}_{2} \mathrm{BDC}=1$,4-benzenedicarboxylic acid) and $\left\{\left[\mathrm{Cd}\left(\mathbf{L}^{1}\right)(1,4-\mathrm{BDC})\right] \cdot 2 \mathrm{H}_{2} \mathrm{O}\right\}_{n}$, which show distorted cages with 8 - and 9-fold interpenetrating modes. ${ }^{3 f}$ The combination of a long flexible $\mathbf{L}^{1}$ ligand with short rigid $1,4-\mathrm{BDC}^{2-}$ ligands reduced the number of interpenetration compared with the complex $\left[\mathrm{CuSO}_{4}\left(\mathbf{L}^{\mathbf{1}}\right)\left(\mathrm{H}_{2} \mathrm{O}\right)_{2}\right]_{n}$ featuring a 12-fold interpenetration. ${ }^{3 c}$ We have also shown that increasing the number of the backbone carbon atom of the neutral spacer ligand not only decreases the degree of interpenetration but also changes the structural type. ${ }^{3 f}$

With this background information, we sought to investigate the influence of geometry and flexibility of the auxiliary dicarboxylate ligand on the structural diversity of coordination networks containing the flexible $N, N^{\prime}$-di(3-pyridyl)suberoamide (L) ligands. The syntheses, structures and properties of $\left\{[\mathrm{Cu}(\mathrm{L})(1,2-\text { pda })] \cdot \mathrm{H}_{2} \mathrm{O}\right\}_{n}\left[\mathrm{H}_{2}(1,2-\right.$ pda $)=1,2$-phenylenediacetic acid $]$, 
1, $\left\{[\mathrm{Cu}(\mathrm{L})(1,3-\text { pda })] \cdot 2 \mathrm{H}_{2} \mathrm{O}\right\}_{n}\left[\mathrm{H}_{2}(1,3-\right.$ pda $)=1,3$-phenylenediacetic acid], 2, and $\left\{[\mathrm{Cu}(\mathrm{L})(1,4-\mathrm{pda})] \cdot 2 \mathrm{H}_{2} \mathrm{O}\right\}_{n} \quad\left[\mathrm{H}_{2}(1,4-p d a)=1,4-\right.$ phenylenediacetic acid], 3 , form the subject of this report.

\section{Experimental}

\section{General procedures}

IR spectra (KBr disk) were obtained using a JASCO FT/IR-460 plus spectrometer. Elemental analyses were performed using a PE 2400 series II CHNS/O analyzer or a HERAEUS VaruoEL analyzer. Thermal gravimetric analyses (TGA) measurements were carried out with a TG/DTA 6200 analyzer from SII Nano Technology Inc. from 30 to $900{ }^{\circ} \mathrm{C}$ at a heating rate of $10{ }^{\circ} \mathrm{C} \mathrm{min}{ }^{-1}$ under nitrogen. Powder X-ray diffraction was carried out using a PANalytical PW3040/60 X'Pert Pro diffractometer with $\operatorname{CuK} \alpha\left(\lambda_{\alpha}=1.54 \AA\right)$ radiation.

\section{Materials}

The reagent $\mathrm{Cu}(\mathrm{OAc})_{2} \cdot \mathrm{H}_{2} \mathrm{O}$ was purchased from SHOWA, 1,3-phenylenediacetic acid from Alfa Aesar, and 1,2-phenylenediacetic acid and 1,4-phenylenediacetic acid from ACROS. The ligand $N, N^{\prime}$-di(3-pyridyl)suberoamide (L) was prepared according to a published procedure. ${ }^{3 d}$

\section{Preparation}

$\left\{[\mathrm{Cu}(\mathrm{L})(1,2-\text { pda })] \cdot \mathrm{H}_{2} \mathrm{O}\right\}_{n}$ 1. A mixture of $\mathrm{Cu}\left(\mathrm{CH}_{3} \mathrm{COO}\right)_{2} \cdot \mathrm{H}_{2} \mathrm{O}$ $(0.020 \mathrm{~g}, 0.10 \mathrm{mmol}), \mathrm{L}(0.033 \mathrm{~g} .0 .10 \mathrm{mmol}), 1,2-\mathrm{H}_{2}$ PDA $(0.019 \mathrm{~g}, 0.10 \mathrm{mmol})$ and $15 \mathrm{~mL}$ of $\mathrm{NaOH}(0.04 \mathrm{M})$ solution was sealed in a $23 \mathrm{~mL}$ Teflon-lined stainless steel autoclave, which was then heated under autogenous pressure to $120^{\circ} \mathrm{C}$ for 2 days. Slow cooling of the reaction system afforded blue crystals suitable for single-crystal X-ray diffraction. Yield: $0.026 \mathrm{~g}$ (43\%). Anal calcd for $\mathrm{C}_{28} \mathrm{H}_{32} \mathrm{~N}_{4} \mathrm{CuO}_{8}\left(\mathrm{MW}=616.12,1+\mathrm{H}_{2} \mathrm{O}\right): \mathrm{C}$, 54.58; H, 5.24; N, 9.09\%. Found: C, 55.28; H, 5.48; N, 8.78\%. IR $\left(\mathrm{cm}^{-1}\right)$ : $3442(\mathrm{~m}), 2931$ (s), $1611(\mathrm{w}), 1545$ (w), $1481(\mathrm{~m})$, 1377 (w), 707 (s).

$\left\{[\mathrm{Cu}(\mathrm{L})(\mathbf{1}, \mathbf{3}-\mathbf{p d a})] \cdot 2 \mathrm{H}_{2} \mathrm{O}\right\}_{n}$ 2. Prepared as described for $\mathbf{1}$, except that $\mathrm{Cu}\left(\mathrm{BF}_{4}\right)_{2} \cdot \mathrm{H}_{2} \mathrm{O}(0.023 \mathrm{~g}, 0.10 \mathrm{mmol})$ and 1,3- $\mathrm{H}_{2} \mathrm{PDA}$ (0.019 g, $0.10 \mathrm{mmol}$ ) were used. Yield: $0.025 \mathrm{~g}$ (40\%). Anal calcd for $\mathrm{C}_{28} \mathrm{H}_{32} \mathrm{CuN}_{4} \mathrm{O}_{7}\left(\mathrm{MW}=600.12,2-\mathrm{H}_{2} \mathrm{O}\right): \mathrm{C}, 56.04$; H, 5.37; N, 9.34\%. Found: C, 55.74; H, 5.20; N, 9.11\%. IR $\left(\mathrm{cm}^{-1}\right)$ : 3267 (s), 1705 (s), 1548 (w), 1483 (s), 1390 (m), 1287 (s), 1158 (s).

$\left\{[\mathbf{C u}(\mathbf{L})(\mathbf{1}, 4-p d a)] \cdot 2 \mathbf{H}_{2} \mathbf{O}\right\}_{n} 3$. Prepared as described for $\mathbf{1}$, except that $1,4-\mathrm{H}_{2}$ PDA $(0.019 \mathrm{~g}, 0.10 \mathrm{mmol})$ was used. Yield: $0.020 \mathrm{~g}$ (32\%). Anal calcd for $\mathrm{C}_{28} \mathrm{H}_{34} \mathrm{~N}_{4} \mathrm{CuO}_{8}(\mathrm{MW}=618.14)$ : C, 54.40; H, 5.54; N, 9.06\%. Found: C, 54.20; H, 5.07; N, 8.89\%. IR (cm $\left.{ }^{-1}\right): 3289(\mathrm{~m}), 3069(\mathrm{~m}), 2940(\mathrm{~m}), 1712(\mathrm{~s}), 1606(\mathrm{~m})$, 1553 (s), 1478 (m), 1380 (s), 1332 (m), 1294 (m), 1156 (m), $776(\mathrm{~m}), 717$ (m).

\section{X-ray crystallography}

The diffraction data for complexes 1-3 were collected with a Bruker AXS SMART APEX II CCD diffractometer at $22^{\circ} \mathrm{C}$, which was equipped with graphite-monochromated Mo K $\alpha$ $\left(\lambda_{\alpha}=0.71073 \AA\right)$ radiation. ${ }^{5}$ Data reduction was carried out by standard methods with the use of a well-established computational procedure. ${ }^{6}$ The structure factors were obtained after Lorentz and polarization corrections. An empirical absorption correction based on "multi-scan" was applied to the data for all complexes. The positions of some of the heavier atoms were located by direct methods and the remaining atoms were found in a series of alternating difference Fourier maps and least-square refinements, except that the hydrogen atoms were added by using the HADD command in SHELXTL 5.10. In complexes 1 and 2 , some of the carbon $[\mathrm{C}(6)-\mathrm{C}(9)$ and $\mathrm{C}(17)-\mathrm{C}(18)$ for 1 and $\mathrm{C}(14)$ for 2] and oxygen [O(1) and $\mathrm{O}(17)$ for 1] atoms are disordered such that two orientations can be found for each disordered atom. Basic information pertaining to crystal parameters and structure refinement is summarized in Table 1. Selected bond distances and angles are listed in Table 2.

\section{Results and discussion}

\section{Structure of 1}

Crystals of 1 conform to the triclinic space group $P \overline{1}$ with one $\mathrm{Cu}$ (II) cation, two halves of two different $\mathrm{L}$ ligands and one 1,2-PDA ${ }^{2-}$ anion in the asymmetric unit. Fig. 1(a) shows the coordination environment of the $\mathrm{Cu}$ (II) metal center, which is five-coordinated by two pyridyl nitrogen atoms from two $\mathbf{L}$ ligands and three oxygen atoms from three 1,2-PDA ${ }^{2-}$ ligands, resulting in a distorted square pyramidal geometry with a $\tau$ value of $0.32 .^{7}$ The $\mathrm{Cu}(\mathrm{II})$ ions are linked together by the $1,2-\mathrm{PDA}^{2-}$ ligands that adopt the $\mu_{3}-\kappa^{1}, \kappa,{ }^{1} \kappa^{1}$ coordination mode to afford 1D looped chains with dinuclear metal units (Fig. 1(b)) which are further connected by the $\mathbf{L}$ ligands through the pyridyl nitrogen atoms to form a 3D structure. In the structure, 1,2-PDA ${ }^{2-}$ interact with the $\mathrm{L}$ ligand through $\mathrm{N}-\mathrm{H} \cdots \mathrm{O}\left(\mathrm{H} \cdots \mathrm{O}=2.02 \AA, \mathrm{N} \cdots \mathrm{O}=2.86 \AA, \angle \mathrm{N}-\mathrm{H}-\mathrm{O}=162^{\circ}\right)$ hydrogen bonds.

If the $\mathrm{Cu}$ (II) cations are defined as 5-coordinated nodes and the 1,2-PDA ${ }^{2-}$ ligands as 3-coordinated nodes, topological analysis reveals that the structure of 1 can be regarded as a 3,5 -coordinated net with the $\left(4^{2} \cdot 6^{5} \cdot 8^{3}\right)\left(4^{2} \cdot 6\right)-3,5 \mathrm{~T} 1$ topology (Fig. 1(c)), as determined using TOPOS. ${ }^{8}$ If the $\mathrm{Cu}_{2}(\mu-\mathrm{COO})_{2}$ dimer is considered as a node, the structure of 1 can be further simplified as a 6-coordinated net with a single $\left(4^{12} \cdot 6^{3}\right)$-pcu topology (Fig. 1(d)). The underlying 3,5T1 net is observed in 81 crystals (interpenetrated in 13) as can be found in TTD TOPOS database. ${ }^{9}$ Interestingly five compounds present $\mathbf{M}_{2}(\mu-\mathrm{COO})_{2}$ dimers that allow the same alternative cluster description of the net as pcu, ${ }^{10}$ with $[\mathrm{Cd}(\operatorname{adp})(\mathrm{bpfp})]_{n}$ [adp = adipate; bpfp $=$ bis(4-pyridylformyl)piperazine $]$ the only one with two different ligands of very different lengths. ${ }^{10 a}$

\section{Structure of 2}

Crystals of 2 conform to the monoclinic space group $C 2 / c$ with the $\mathrm{Cu}(\mathrm{II})$ cation on the inversion center, with half of $\mathbf{L}$ 
Table 1 Crystal data for complexes 1-3

\begin{tabular}{|c|c|c|c|}
\hline Compound & 1 & 2 & 3 \\
\hline$F_{\mathrm{w}}$ & 600.12 & 618.13 & 618.13 \\
\hline Space group & $P \overline{1}$ & $\mathrm{C} 2 /_{\mathrm{C}}$ & Pmna \\
\hline$a, \AA$ & $8.3326(4)$ & $29.5458(9)$ & $15.8723(8)$ \\
\hline$b, \AA$ & $10.3780(5)$ & $6.3519(2)$ & 12.1103(6) \\
\hline$c, \AA$ & $16.5929(9)$ & $18.5588(6)$ & $14.8539(7)$ \\
\hline$\gamma, \circ$ & $74.322(3)$ & 90 & 90 \\
\hline$V, \AA^{3}$ & $1350.09(12)$ & 2841.88(15) & $2855.2(2)$ \\
\hline$Z$ & 2 & 4 & 4 \\
\hline$D_{\text {calc }}, \mathrm{g} \mathrm{cm}^{-3}$ & 1.476 & 1.445 & 1.438 \\
\hline$F(000)$ & 626 & 1292 & 1292 \\
\hline$\mu(\mathrm{Mo} \mathrm{K} \alpha), \mathrm{mm}^{-1}$ & 0.863 & 0.825 & 0.821 \\
\hline Quality-of-fit indicator ${ }^{c}$ & 1.028 & 1.009 & 1.053 \\
\hline Final $R$ indices $[I>2 \sigma(I)]^{a, b}$ & $R_{1}=0.0652, \mathrm{w} R_{2}=0.1670$ & $R_{1}=0.0624, \mathrm{w} R_{2}=0.1577$ & $R_{1}=0.0750, \mathrm{w} R_{2}=0.1865$ \\
\hline$R$ indices (all data) & $R_{1}=0.1205, \mathrm{w} R_{2}=0.2012$ & $R_{1}=0.1121, \mathrm{w} R_{2}=0.1864$ & $R_{1}=0.1229, \mathrm{w} R_{2}=0.2242$ \\
\hline
\end{tabular}

Table 2 Selected bond lengths $(\AA)$ and angles $\left({ }^{\circ}\right)$ for complexes 1-3

\begin{tabular}{llll}
\hline 1 & & & \\
\hline $\mathrm{Cu}-\mathrm{O}(6 \mathrm{~A})$ & $1.959(4)$ & $\mathrm{Cu}-\mathrm{O}(3)$ & $1.997(3)$ \\
$\mathrm{Cu}-\mathrm{N}(1)$ & $2.001(5)$ & $\mathrm{Cu}-\mathrm{N}(3)$ & $2.006(5)$ \\
$\mathrm{Cu}-\mathrm{O}(5 \mathrm{~B})$ & $2.173(4)$ & & \\
& & & \\
$\mathrm{O}(6 \mathrm{~A})-\mathrm{Cu}-\mathrm{O}(3)$ & $150.3(2)$ & $\mathrm{O}(6 \mathrm{~A})-\mathrm{Cu}-\mathrm{N}(1)$ & $85.3(2)$ \\
$\mathrm{O}(3)-\mathrm{Cu}-\mathrm{N}(1)$ & $90.9(2)$ & $\mathrm{O}(6 \mathrm{~A})-\mathrm{Cu}-\mathrm{N}(3)$ & $88.0(2)$ \\
$\mathrm{O}(3)-\mathrm{Cu}-\mathrm{N}(3)$ & $90.9(2)$ & $\mathrm{N}(1)-\mathrm{Cu}-\mathrm{N}(3)$ & $169.5(2)$ \\
$\mathrm{O}(6 \mathrm{~A})-\mathrm{Cu}-\mathrm{O}(5 \mathrm{~B})$ & $122.9(2)$ & $\mathrm{O}(3)-\mathrm{Cu}-\mathrm{O}(5 \mathrm{~B})$ & $86.8(1)$ \\
$\mathrm{N}(1)-\mathrm{Cu}-\mathrm{O}(5 \mathrm{~B})$ & $97.0(2)$ & $\mathrm{N}(3)-\mathrm{Cu}-\mathrm{O}(5 \mathrm{~B})$ & $93.4(2)$ \\
\hline 2 & & & \\
& & & \\
\hline $\mathrm{Cu}-\mathrm{O}(2 \mathrm{~A})$ & $1.952(3)$ & $\mathrm{Cu}-\mathrm{O}(2)$ & $2.011(4)$ \\
$\mathrm{Cu}-\mathrm{N}(1)$ & $2.011(4)$ & $\mathrm{Cu}-\mathrm{N}(1 \mathrm{~A})$ & $90.0(2)$ \\
& & & $90.0(2)$ \\
$\mathrm{O}(2 \mathrm{~A})-\mathrm{Cu}-\mathrm{O}(2)$ & 180.0 & $\mathrm{O}(2 \mathrm{~A})-\mathrm{Cu}-\mathrm{N}(1)$ & \\
$\mathrm{O}(2)-\mathrm{Cu}-\mathrm{N}(1)$ & $90.0(2)$ & $\mathrm{O}(2 \mathrm{~A})-\mathrm{Cu}-\mathrm{N}(1 \mathrm{~A})$ & \\
$\mathrm{O}(2)-\mathrm{Cu}-\mathrm{N}(1 \mathrm{~A})$ & $90.0(2)$ & $\mathrm{N}(1)-\mathrm{Cu}-\mathrm{N}(1 \mathrm{~A})$ & 180.0 \\
\hline 3 & & & $1.970(4)$ \\
\hline $\mathrm{Cu}-\mathrm{O}(4 \mathrm{~A})$ & $1.949(5)$ & $\mathrm{Cu}-\mathrm{O}(2)$ & $2.046(4)$ \\
$\mathrm{Cu}-\mathrm{N}(1 \mathrm{~B})$ & $2.046(4)$ & $\mathrm{Cu}-\mathrm{N}(1)$ & $87.4(1)$ \\
$\mathrm{Cu}-\mathrm{O}(2 \mathrm{C})$ & $2.393(5)$ & & $82.4(1)$ \\
$\mathrm{O}(4 \mathrm{~A})-\mathrm{Cu}-\mathrm{O}(2)$ & $177.4(2)$ & $\mathrm{O}(4 \mathrm{~A})-\mathrm{Cu}-\mathrm{N}(1 \mathrm{~B})$ & \\
$\mathrm{O}(2)-\mathrm{Cu}-\mathrm{N}(1 \mathrm{~B})$ & $92.7(1)$ & $\mathrm{O}(4 \mathrm{~A})-\mathrm{Cu}-\mathrm{N}(1)$ & \\
$\mathrm{O}(2)-\mathrm{Cu}-\mathrm{N}(1)$ & $92.7(1)$ & $\mathrm{N}(1 \mathrm{~B})-\mathrm{Cu}-\mathrm{N}(1)$ & \\
$\mathrm{O}(4 \mathrm{~A})-\mathrm{Cu}-\mathrm{O}(2 \mathrm{C})$ & $95.6(2)$ & $\mathrm{O}(2)-\mathrm{Cu}-\mathrm{O}(2 \mathrm{C})$ & \\
$\mathrm{N}(1 \mathrm{~B})-\mathrm{Cu}-\mathrm{O}(2 \mathrm{C})$ & $92.0(1)$ & $\mathrm{N}(1)-\mathrm{Cu}-\mathrm{O}(2 \mathrm{C})$ & \\
& & &
\end{tabular}

Symmetry transformations used to generate equivalent atoms: (A) $x-1, y, z$. (B) $-x+1,-y+1,-z+1$ for 1 ; (A) $-x+1 / 2,-y+1 / 2,-z+1$ for 2 ; (A) $x, y-1, z$. (B) $-x+1, y, z$. (C) $-x+1,-y+1,-z+1$ for 3 .

and $1,3-\mathrm{PDA}^{2-}$ ligands in the asymmetric unit. The coordination environment of the $\mathrm{Cu}(\mathrm{II})$ metal center is shown in
Fig. 2(a), which is four-coordinated by two pyridyl nitrogen atoms from two $\mathbf{L}$ ligands and two oxygen atoms from two $1,3-$ PDA $^{2-}$ ligands, resulting in a distorted square planar geometry. Two weak $\mathrm{Cu} \cdots \mathrm{O}$ interactions with a distance of $2.620(4) \AA$ are also observed in the axial positions. The $\mathrm{Cu}$ (II) ions are linked together by the $1,3-\mathrm{PDA}^{2-}$ ligands that adopt the $\mu_{2}-\kappa^{1}, \kappa,{ }^{1}$ coordination mode to afford $1 \mathrm{D}$ linear chains (Fig. 2(b)), which are further linked by the $\mathbf{L}$ ligands through the pyridyl nitrogen atoms to form a $3 \mathrm{D}$ structure.

Each $\mathrm{Cu}(\mathrm{II})$ ion is connected to four neighboring $\mathrm{Cu}(\mathrm{II})$ ions through two 1,3-PDA ${ }^{2-}$ and two $\mathrm{L}$ ligands with distances of $12.08 \AA$ (through 1,3-PDA ${ }^{2-}$ ) and 21.69 (through $\mathbf{L}$ ), and thus each $\mathrm{Cu}(\mathrm{II})$ ion can be considered as a four-coordinated node. Topological analysis reveals that complex 2 forms a 5-fold interpenetrated 3D coordination network with the $\left(6^{5} \cdot 8\right)$-cds topology (Fig. 2(c) and (d)). The 5 nets are related by a single translation $[0,1,0]$; thus they belong to Class Ia. ${ }^{11}$ According to the TTO database of TOPOS, ${ }^{8,9}$ the maximum number of interpenetrations that has been reported for cds in coordination networks is four and there are three examples. Complex 2 thus exhibits the maximum number of interpenetrations presently known for cds. The five interpenetrated nets are joined in a single net by $\mathrm{N}-\mathrm{H} \cdots \mathrm{O}\left[\mathrm{H} \cdots \mathrm{O}=2.06 \AA, \mathrm{N} \cdots \mathrm{O}=2.90 \AA \angle \mathrm{N}-\mathrm{H} \cdots \mathrm{O}=164^{\circ}\right]$ hydrogen bonds from the amine hydrogen atoms of the $\mathbf{L}$ ligands to the carboxylate oxygen atoms of the 1,3-PDA ${ }^{2-}$ ligands (Fig. S4 $\dagger$ ). The water molecules are also involved in hydrogen bonds with the 1,3-PDA ${ }^{2-}$ ligands through $\mathrm{O}-\mathrm{H} \cdots \mathrm{O}$ $(\mathrm{H} \cdots \mathrm{O}=1.91$ and $2.25 \AA$, $\mathrm{O} \cdots \mathrm{O}=2.76$ and $3.02 \AA, \angle \mathrm{O}-\mathrm{H} \cdots \mathrm{O}=$ 179 and $\left.151^{\circ}\right)$. 

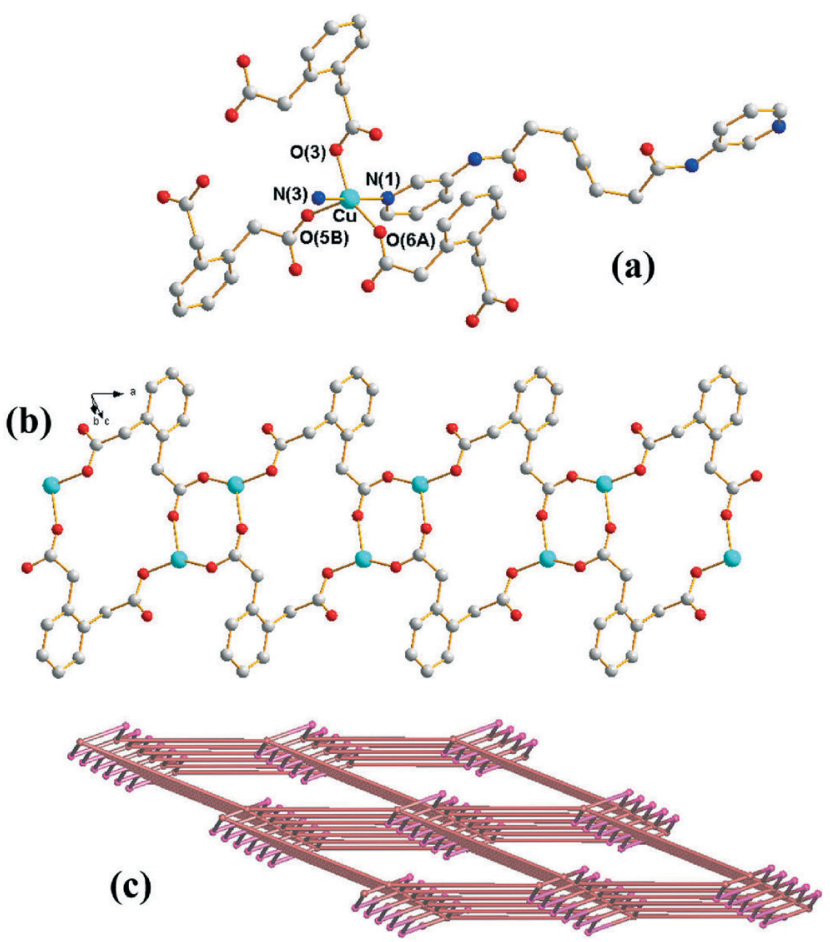

(d)

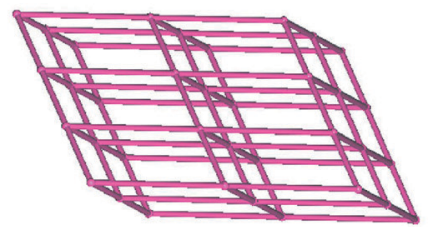

Fig. 1 (a) Coordination environment of the $\mathrm{Cu}(\mathrm{II})$ ion in 1 . Symmetry transformations used to generate equivalent atoms: (A) $x-1, y, z$. (B) $-x+1,-y+1,-z+1$. (b) The $\mathrm{Cu}($ II) ions are interlinked by $1,2-\mathrm{PDA}^{2-}$ ligands to give $1 \mathrm{D}$ looped chains. (c) A drawing showing the 3,5 -coordinated net with $\left(4^{2} \cdot 6^{5} \cdot 8^{3}\right)\left(4^{2} \cdot 6\right)-3,5 T 1$ topology. (d) A drawing showing the 6 -coordinated net with $\left(4^{12} \cdot 6^{3}\right)$-pcu topology.

\section{Structure of 3}

Crystals of 3 conform to the orthorhombic space group Pmna with the $\mathrm{Cu}$ (II) cation lying on a mirror plane, with half of $\mathbf{L}$ and 1,4-PDA ${ }^{2-}$ ligand and two cocrystallized water molecules in the asymmetric unit. Fig. 3(a) shows the coordination environment of the $\mathrm{Cu}$ (II) metal center, which is five-coordinated by two pyridyl nitrogen atoms from two $\mathbf{L}$ ligands and three oxygen atoms from three $1,4-\mathrm{PDA}^{2-}$ ligands, resulting in a distorted square pyramidal geometry with a $\tau$ value of 0.06 . The $\mathrm{Cu}(\mathrm{II})$ ions are bridged by the $1,4-\mathrm{PDA}^{2-}$ anions that adopt the $\mu_{3}-\kappa^{1}, \kappa^{1}, \kappa^{1}$ coordination mode to form dinuclear units with a $\mathrm{Cu} \cdots \mathrm{Cu}$ distance of 3.309(1) $\AA$, which are further linked by the $\mathbf{L}$ ligands and the $1,4-\mathrm{PDA}^{2-}$ ligands to form a 1D self-catenated coordination network (Fig. 3(b) and (c)). It can be seen that each 34-membered ring that involves two $\mathrm{Cu}(\mathrm{II})$ ions and two $\mathbf{L}$ ligands is penetrated by two 1,4-PDA ${ }^{2-}$ ligands. Adjacent 1D chains are connected by water molecules through $\mathrm{N}-\mathrm{H} \cdots \mathrm{O}(\mathrm{H} \cdots \mathrm{O}=2.14 \AA$, $\mathrm{N} \cdots \mathrm{O}=3.00 \AA$, $\angle \mathrm{N}-\mathrm{H} \cdots \mathrm{O}=177^{\circ}$ ) hydrogen bonds originating from the amine hydrogen atoms of the $\mathbf{L}$ ligands to the water

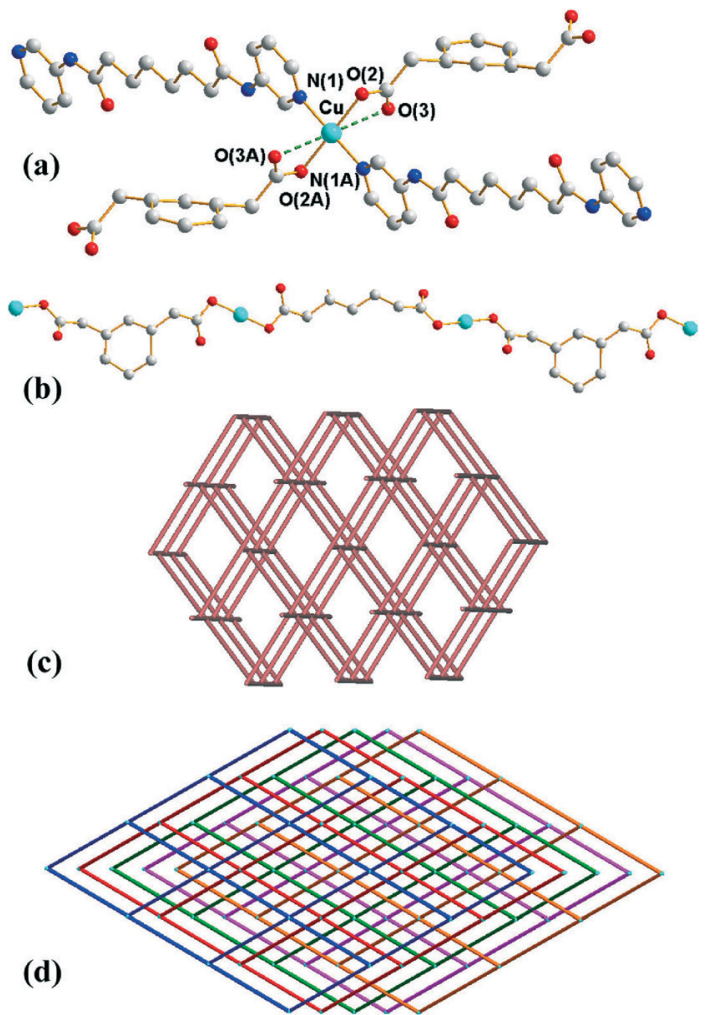

Fig. 2 (a) Coordination environment of the $\mathrm{Cu}(\mathrm{II})$ ion in 2. Symmetry transformations used to generate equivalent atoms: (A) $-x+1 / 2,-y+1 / 2$, $-z+1$. (b) The $\mathrm{Cu}(॥)$ ions are interlinked by $1,3-$ PDA $^{2-}$ ligands to give 1D linear chains. (c) A drawing showing the 4-connected net with $\left(6^{5} \cdot 8\right)$-cds topology. (d) A drawing showing the 5 -fold interpenetrated network.

molecules and $\mathrm{O}-\mathrm{H} \cdots \mathrm{O}(\mathrm{H} \cdots \mathrm{O}=1.82-1.93 \AA$, $\mathrm{O} \cdots \mathrm{O}=2.65-$ $\left.2.76 \AA \angle \mathrm{O}-\mathrm{H}^{\cdots} \mathrm{O}=164-168^{\circ}\right)$ hydrogen atoms to the carboxylate oxygen atoms of 1,3-PDA ${ }^{2-}$ ligands (Fig. S5 $\dagger$ ).

Self-catenated nets are single nets that exhibit the peculiar feature of containing shortest rings through which pass other components of the same network. ${ }^{12}$ Catenation can be identified by the presence of edges that thread a ring; in other words, they share at least one point with a disc-like film bounded by the ring. Since infinite nets with three lattice vectors inevitably contain large cycles that are threaded, we restrict "rings" to smallest cycles in the net that cannot be decomposed into sums of still smaller cycle, such as "strong rings". ${ }^{13}$ If both the threaded edge and the ring belong to a single connected component of the structure, it is self-catenated. Most coordination networks showing the feature of self-catenation are 3D nets, ${ }^{14}$ and there are only several 2D cases that are presently known. ${ }^{15}$ Complex 3 thus appears to be the first $1 \mathrm{D}$ coordination network showing self-catenation.

This network has an additional feature that is worth noting, namely, it is entangled. To see this, it is convenient to redraw complex 3 as a "ladder" (with single back- "/" and paired forward-slash "I" stringers), as shown in Fig. 4(a). Here the structure has been redrawn to preserve its topology. Further, although its geometric details (such as vertex 

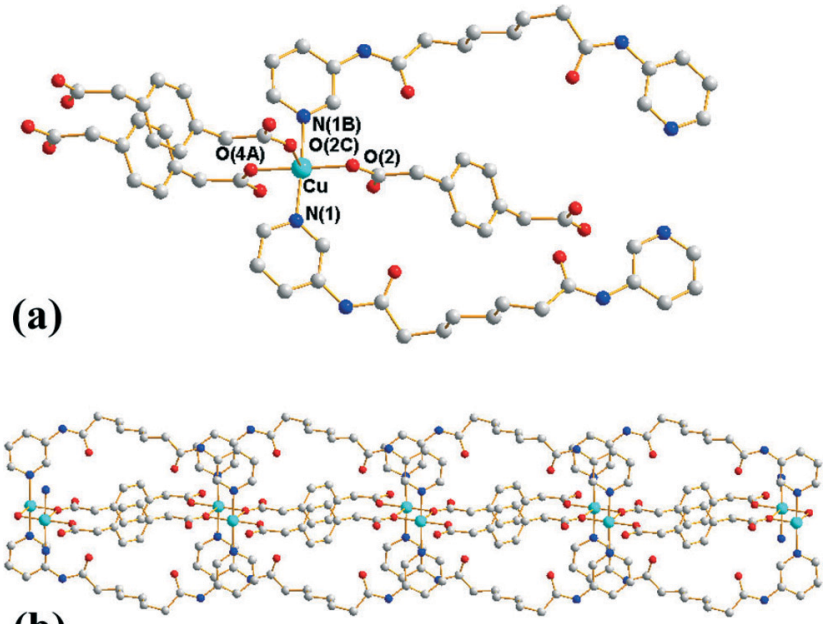

(b)

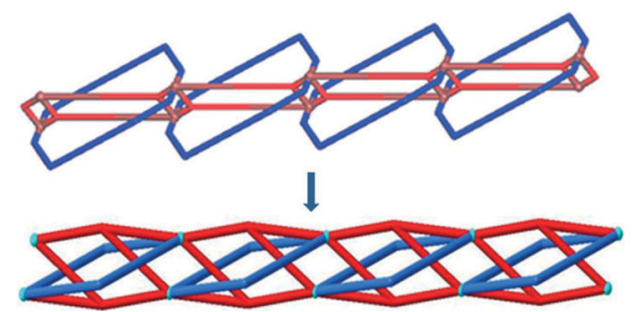

(c)

Fig. 3 (a) Coordination environment of the $\mathrm{Cu}(॥)$ ion in 3. Symmetry transformations used to generate equivalent atoms: (A) $x, y-1, z$. (B) $-x+1, y, z$. (C) $-x+1,-y+1,-z+1$. (b) A drawing showing the 1D chain. (c) A simplified drawing showing the 1D self-catenated structure.

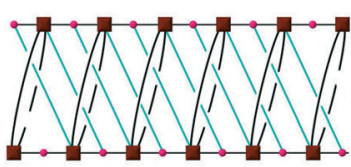

(a)
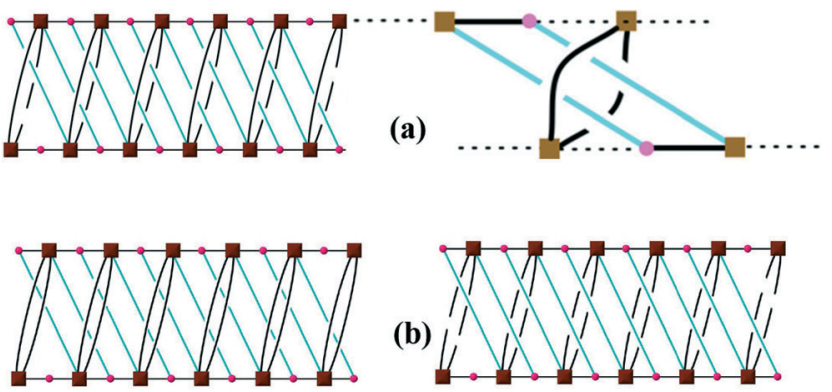

(b)

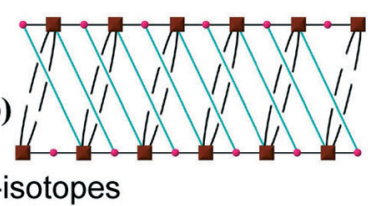

untangled-isotopes

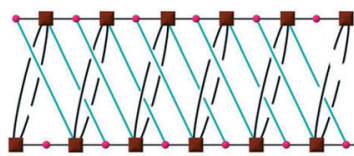

(c)
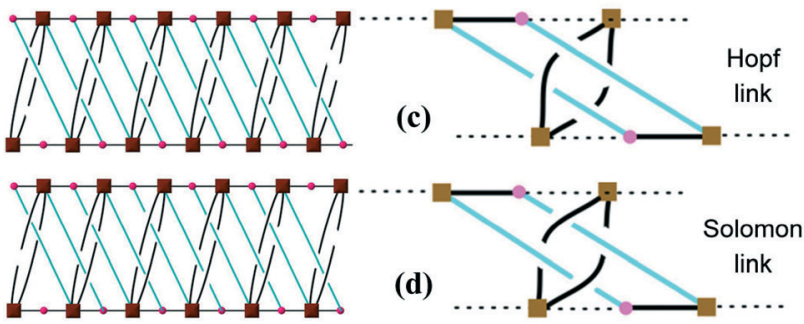

tangled-isotopes

Fig. 4 (a) A schematic drawing of 3. (b) Two equivalent representations of the same arrangement but NOT entangled. (c) A drawing showing the Hopf links. (d) A drawing showing the Solomon links.

locations and bonding geometries) are distorted, its tangled features, namely, the mutual catenation of edges and cycles, are also preserved. This means that the structure in Fig. 4(a) is an equivalent "tangled-isotope" that preserves both the topology and the edge crossings. Here we adopt the term "tangled-isotope" from the mathematical operation of "ambient isotopy", corresponding to distortions of a structure that do not alter its inherent entanglement. ${ }^{16}$ The ring formed by a pair of forward-slashes - one above and one below - sharing two vertices is threaded by (two parallel) back-slashes, describing the self-catenation. A simpler, untangled-isotope is that whose pair of forward-slash stringers is either both above or both below the back-slash stringers, as illustrated in Fig. 4(b). The edges of this untangled-isotope reticulate a cylinder without any edge crossings (with forward- and backslashes running on opposite faces of the cylinder). In contrast, the edges of complex 3 cannot reticulate a cylinder without edge crossings: a multi-handled surface made of a pair of parallel cylinders with connecting tubes is necessary to support a crossing-free reticulation. Since this latter surface is topologically more complex than the simple cylinder, complex 3 is (according to the definition advanced in ref. 15) entangled.

Closely related tangled-isotopes to complex 3 are knotted, with more common signatures of entangled networks in terms of constituent knots or links. For example, permutations of the crossings between forward- and back-slash stringers result in patterns containing threaded links, or pairs of catenated rings. Two of the simpler tangled-isotopes are those with Hopf links (Fig. 4(c)) and Solomon links (Fig. 4(d)). In stark contrast to complex 3 , both of these are tangled-isotopes since they contain pairs of interwoven cycles that cannot be separated without breaking edges, as illustrated in the figures. They are distinguished by the crossings of one cycle (blue in the figures) with the interlocked (black) cycle. If we denote crossings of blue edges over/under black edges by the symbols "+"/“"-", an anticlockwise walk around a blue cycle made of four edges in Fig. 4(c) crosses black edges in the order " -+++ " (or cyclic permutations); the analogous walk in Fig. 4(d) is "+-+-". These sequences of over and under crossings characterise Hopf and Solomon links, respectively (see, for example, ref. 17). However, the entanglement in complex 3 is a peculiar and hitherto unrecognised one. It has neither knots nor links. Further, it is also free of "ravels" - a subtle entanglement mode distinct from knots or links - that can be formed in tangled nets. ${ }^{18}$ To date, knots, links and ravels have all been identified in metal-organic complexes. ${ }^{2,19}$ Complex 3 is, to our knowledge, the first example of a tangled net that does not contain knots, links or ravels, thus exemplifying a new mode of entanglement.

\section{Ligand conformations and structural comparisons}

Twenty ligand conformations can be found for $\mathbf{L}$ if the $\mathrm{A}$ and $\mathrm{G}$ conformations are given when the $\mathrm{C}-\mathrm{C}-\mathrm{C}-\mathrm{C}$ torsion angle $(\theta)$ is $0 \leq \theta \leq 90^{\circ}$ and $90 \leq \theta<180^{\circ}$, respectively. In 
addition, based on the relative orientation of the $\mathrm{C}=\mathrm{O}$ groups, each conformation can adopt a cis or a trans arrangement. Moreover, due to the difference in the orientations of the pyridyl nitrogen atom positions, three more orientations, anti-anti, syn-anti and syn-syn, based on the relative positions of the pyridyl nitrogen and amide oxygen atom can also be derived (Fig. 5).

Table 3 lists all of the ligand conformations of the $\mathbf{L}$ ligand in complexes 1-3. The structural parameters of the reported complexes $[\mathrm{Cu}(\mathbf{L})(1,2-\mathrm{bdc})]_{n}\left(1,2-\mathrm{H}_{2} \mathrm{bdc}=1,2-\right.$ benzenedicarboxylic acid) and $\left[\mathrm{Cu}(\mathrm{L})(1,3-\mathrm{bdc})\left(\mathrm{H}_{2} \mathrm{O}\right) \cdot 3 \mathrm{H}_{2} \mathrm{O}\right]_{n}$ $\left(1,3-\mathrm{H}_{2}\right.$ bdc $=1,3$-benzenedicarboxylic acid) that contain $\mathbf{L}$ are also shown for comparison. ${ }^{20}$ A comparison of these structures shows that the flexibility of the dicarboxylate ligands, in which the $\mathrm{pda}^{2-}$ ligands in 1-3 hold two more $\mathrm{CH}_{2}$ groups than the bdc ${ }^{2-}$ ligands, significantly affects the structural diversity. In 1 and $[\mathrm{Cu}(1,2-\mathrm{bdc})(\mathrm{L})]_{n}$, the $1,2-\mathrm{pda}^{2-}$ and $1,2-$ bdc $^{2-}$ ligands adopt the $\mu^{3}-\kappa^{1}, \kappa^{1}, \kappa^{1}$ mode and $\mu^{2}-\kappa^{2}, \kappa^{2}$ mode, respectively, resulting in AAAAA trans anti-anti and GGAGG trans anti-anti conformations for the $\mathbf{L}$ ligands in $\mathbf{1}$ and AAAAA trans syn-syn conformation for the $\mathbf{L}$ ligands in<smiles>[C-][n+]1cccc(NC(=O)CCCCCCC(=O)Nc2cccnc2)c1</smiles><smiles>O=C(CCCCCCC(=O)Nc1cccnc1)Nc1cccnc1</smiles>

(c)

Fig. 5 Three possible orientations for the pyridyl nitrogen atoms of the L ligand: (a) syn-syn (b) syn-anti (c) anti-anti.
$[\mathrm{Cu}(1,2-\mathrm{bdc})(\mathrm{L})]_{n}$, forming a 3D structure with 3,5T1 topology and a 2D wavelike structure, respectively. In contrast, the 1,3-pda ${ }^{2-}$ and 1,3-bdc ${ }^{2-}$ ligands of 2 and $\left[\mathrm{Cu}(1,3-\mathrm{bdc})(\mathrm{L})\left(\mathrm{H}_{2} \mathrm{O}\right)\right] \cdot 3 \mathrm{H}_{2} \mathrm{O}$ adopt the same $\mu^{2}-\kappa^{1}, \kappa^{1}$ coordination mode, but lead to the formation of AAAAA trans anti-anti conformation for the $\mathbf{L}$ ligands in 2 and GAAAG trans syn-syn and AAAAA trans syn-syn conformations for the $\mathbf{L}$ ligands in $\left[\mathrm{Cu}(1,3-\mathrm{bdc})(\mathrm{L})\left(\mathrm{H}_{2} \mathrm{O}\right)\right] \cdot 3 \mathrm{H}_{2} \mathrm{O}$, resulting in 5- and 3 -fold interpenetration, respectively. In each single cds structure, the distances between the $\mathrm{Cu}$ (II) nodes are $12.08 \AA$ (through 1,3-pda ${ }^{2-}$ ) and $21.69 \AA$ (through $\mathrm{L}$ ) for 2 significantly longer than those of $9.66 \AA$ (through 1,3-bdc ${ }^{2-}$ ) and $19.46 \AA$ (through $\mathbf{L}$ ) for $\left[\mathrm{Cu}(1,3-b d c)(\mathrm{L})\left(\mathrm{H}_{2} \mathrm{O}\right)\right] \cdot 3 \mathrm{H}_{2} \mathrm{O}$, indicating the importance of the length of the spacer ligand in determining the number of interpenetrations. The cis- and trans-conformations of the phenylenediacetate ligands have been investigated recently. ${ }^{21}$ For example, in the 1D ladder-like silver(I) complex $\left[\mathrm{Ag}_{3}(\text { cis-pda)(bipy })_{3}\right]_{n} \cdot 0.5 n$ (trans-pda) $\cdot 5 n \mathrm{H}_{2} \mathrm{O}$ (bipy = 4,4'-bipyridine), both of the two different formations (cis- and trans) of the 1,2-pda ${ }^{2-}$ ligands were observed. ${ }^{21 a}$ Inspection of the structures of the three isomeric $\mathrm{pda}^{2-}$ ligands in 1-3 reveals that they all adopt the trans conformation.

\section{Thermal properties}

In order to estimate the stability of the frameworks, thermogravimetric analysis (TGA) of complexes 1-3 was carried out in nitrogen from 30 to $900{ }^{\circ} \mathrm{C}$ (Fig. S6 and Table S1 $\dagger$ ). The TGA curve of 1 shows the gradual weight loss of water molecules (calculated $5.02 \%$; observed $3.53 \%$ ) in 50-190 ${ }^{\circ} \mathrm{C}$. The weight loss between 200 and $460{ }^{\circ} \mathrm{C}$ corresponds to the decomposition of the $\mathbf{L}$ ligand and 1,4-pda ${ }^{2-}$ ligand (calculated $84.96 \%$; observed $86.41 \%$ ). The TGA curve of 2 shows the gradual weight loss of water molecules (calculated $3.00 \%$; observed $2.16 \%$ ) in $45-200{ }^{\circ} \mathrm{C}$, and the weight loss of $86.19 \%$ between 200 and $510{ }^{\circ} \mathrm{C}$ corresponds to the decomposition of the $\mathbf{L}$ ligand and 1,4-pda ${ }^{2-}$ ligand (calculated $86.41 \%$ ). For complex 3 , the TGA curve shows the gradual weight loss of water molecules (calculated $5.83 \%$, observed $6.56 \%$ ) in $50-200{ }^{\circ} \mathrm{C}$. The weight loss of $83.26 \%$ between 200 and $460{ }^{\circ} \mathrm{C}$ can be ascribed to the decomposition of the $\mathbf{L}$ ligand and 1,4-pda ${ }^{2-}$ ligand (calculated $83.89 \%$ ). The TGA results show that the weight losses that are due to the removal of cocrystallized and the bonded water molecules

Table 3 Some important parameters of complexes 1-3, $[\mathrm{Cu}(\mathrm{L})(1,2-\mathrm{BDC})]_{n}$ and $\left\{\left[\mathrm{Cu}(\mathrm{L})(1,3-\mathrm{BDC})\left(\mathrm{H}_{2} \mathrm{O}\right)\right] \cdot 3 \mathrm{H}_{2} \mathrm{O}\right\}_{n}$

\begin{tabular}{|c|c|c|c|}
\hline Complex & $\begin{array}{l}\text { Coordination mode of } \\
\text { the dicarboxylate ligand }\end{array}$ & Conformation of $\mathbf{L}$ & Structure \\
\hline$\left\{\left[\mathrm{Cu}(\mathrm{L})(1,2 \text {-pda) }) \cdot \mathrm{H}_{2} \mathrm{O}\right\}_{n}, \mathbf{1}\right.$ & $\mu^{3}-\kappa^{1}, \kappa^{1}, \kappa^{1}$ & $\begin{array}{l}\text { AAAAA trans anti-anti } \\
\text { GGAGG trans anti-anti }\end{array}$ & $3,5 \mathrm{~T} 1$ \\
\hline$\left\{[\mathrm{Cu}(\mathbf{L})(1,3-\text { pda })] \cdot 2 \mathrm{H}_{2} \mathrm{O}\right\}_{n}, 2$ & $\mu^{2}-\kappa^{1}, \kappa^{1}$ & AAAAA trans anti-anti & cds, 5-fold interpenetration \\
\hline$\left\{[\mathrm{Cu}(\mathrm{L})(1,4-\text { pda })] \cdot 2 \mathrm{H}_{2} \mathrm{O}\right\}_{n}, 3$ & $\mu_{3}-\kappa^{1}, \kappa^{1}, \kappa^{1}$ & GAAAG cis syn-syn & 1D self-catenation \\
\hline$[\mathrm{Cu}(\mathrm{L})(1,2-\mathrm{bdc})]_{n}$ & $\mu^{2}-\kappa^{2}, \kappa^{2}$ & AAAAA trans syn-syn ${ }^{a}$ & sql \\
\hline$\left\{\left[\mathrm{Cu}(\mathrm{L})(1,3-\mathrm{bdc})\left(\mathrm{H}_{2} \mathrm{O}\right)\right] \cdot 3 \mathrm{H}_{2} \mathrm{O}\right\}_{n}$ & $\mu^{2}-\kappa^{1}, \kappa^{1}$ & GAAAG trans $s y n-s y n^{a}$ & cds, 3-fold interpenetration \\
\hline
\end{tabular}


occurred in $45-200{ }^{\circ} \mathrm{C}$, and the organic ligands decomposed at temperatures above $200{ }^{\circ} \mathrm{C}$. The different structural types of 1-3 do not affect the decomposition of the organic ligands significantly. The PXRD patterns of complexes 1-3 heated at $150{ }^{\circ} \mathrm{C}$ for 3 hours shown in Fig. $\mathrm{S} 1-\mathrm{S} 3 \dagger$ reveal that their structures are stable upon solvent removal. It is noted that the solvent-accessible volumes of complexes 1-3 calculated with PLATON ${ }^{22}$ after the removal of water molecules are as small as 67.5, 161.0 and $196.2 \AA^{3}$, which are 5.0\%, 5.7\% and $6.9 \%$ of each of the unit cell volumes, respectively.

\section{Conclusion}

Three new coordination networks containing $\mathbf{L}$ and isomeric phenylenediacetate ligands have been successfully synthesized under hydrothermal conditions. The different structures in 1-3 can be attributed to the ligand isomerism of the $\mathrm{PDA}^{2-}$ ligands that result in different $\mathbf{L}$ conformations. Obviously, the $\mathbf{L}$ ligands are sufficiently flexible to adjust to the stereochemical requirements for the formation of complexes 1-3, which adopt the conformations that maximize their intra- and intermolecular forces. To our best knowledge, complex $\mathbf{1}$ is a rare example with two different ligands of very different lengths, with underlying 3,5T1 nets further simplified to pcu; complex 2 shows the maximum number of interpenetrations presently known for cds coordination networks; and complex 3 is the first 1D self-catenated, entangled, unknotted and unravelled coordination network.

\section{Acknowledgements}

We are grateful for the Ministry of Science and Technology of the Republic of China for support. DMP acknowledges the Ministry of Education and Science of Russia (grant 14.B25.31.0005).

\section{References}

1 (a) E. R. T. Tiekink and J. J. Vittal, Frontiers in Crystal Engineering, John Wiley \& Sons, Ltd., England, 2006; (b) C. B. Aakeröy, N. R. Champness and C. Janiak, CrystEngComm, 2010, 12, 22; (c) M. O'Keeffe, M. A. Peskov, S. J. Ramsden and O. M. Yaghi, Acc. Chem. Res., 2008, 41, 1782; (d) J. R. Li, R. J. Kuppler and H. C. Zhou, Chem. Soc. Rev., 2009, 38, 1477; (e) M. D. Allendorf, C. A. Bauer, R. K. Bhakta and R. J. T. Houk, Chem. Soc. Rev., 2009, 38, 1330; $(f)$ B. Moulton and M. J. Zaworotko, Chem. Rev., 2001, 101, 1629; $(g)$ W. L. Leong and J. J. Vittal, Chem. Rev., 2011, 111, 688; $(h)$ Z. Niu and H. W. Gibson, Chem. Rev., 2009, 109, 6014.

2 (a) L. Carlucci, G. Ciani and D. M. Proserpio, Coord. Chem. Rev., 2003, 246, 247; (b) D. M. Proserpio, Nat. Chem., 2010, 2, 435; (c) L. Carlucci, G. Ciani, D. M. Proserpio, T. G. Mitina and V. A. Blatov, Chem. Rev., 2014, 114, 7557; (d) G.-P. Yang, L. Hou, X.-J. Luan, B. Wu and Y.-Y. Wang, Chem. Soc. Rev., 2012, 41, 6992; (e) J.-Q. Liu, Y.-Y. Wang, P. Liu, Z. Dong, Q.-Z. Shia and S. R. Batten, CrystEngComm, 2009, 11, 1207.
3 See, for examples: (a) L. Carlucci, G. Ciani, D. M. Proserpio and S. Rizzato, CrystEngComm, 2002, 4, 121; (b) H.-C. Chen, H.-L. Hu, Z.-K. Chan, C.-W. Yeh, H.-W. Jia, C.-P. Wu, J.-D. Chen and J.-C. Wang, Cryst. Growth Des., 2007, 7, 698; (c) Y.-F. Hsu, C.-H. Lin, J.-D. Chen and J.-C. Wang, Cryst. Growth Des., 2008, 8, 1094; (d) Y.-F. Hsu, H.-L. Hu, C.-J. Wu, C.-W. Yeh, D. M. Proserpio and J.-D. Chen, CrystEngComm, 2009, 11, 168; (e) Y.-F. Hsu, W. Hsu, C.-J. Wu, P.-C. Cheng, C.-W. Yeh, W.-J. Chang, J.-D. Chen and J.-C. Wang, CrystEngComm, 2010, 12, 702; $(f)$ J.-J. Cheng, Y.-T. Chang, C.-J. Wu, Y.-F. Hsu, C.-H. Lin, D. M. Proserpio and J.-D. Chen, CrystEngComm, 2012, 14, 537.

4 (a) M. Du, X.-J. Jiang and X.-J. Zhao, Chem. Commun., 2005, 5521; (b) M. Du, Z.-H. Zhang, X.-G. Wang, L.-F. Tang and X.-J. Zhao, CrystEngComm, 2008, 10, 1855; (c) M. Du, X.-J. Jiang and X.-J. Zhao, Inorg. Chem., 2007, 46, 3984; $(d)$ J. Yang, J.-F. Ma, Y.-Y. Liu, J.-C. Ma and S. R. Batten, Cryst. Growth Des., 2009, 9, 1894.

5 Bruker AXS, APEX2, V2008.6, SADABS V2008/1, SAINT V7.60A, SHELXTL V6.14, Bruker AXS Inc., Madison, Wisconsin, USA, 2008.

6 G. M. Sheldrick, Acta Crystallogr., Sect. A: Found. Crystallogr., 2008, 64, 112.

7 A. W. Addison, T. N. Rao, J. Reedijik, J. V. Rijn and G. C. Verschoor, J. Chem. Soc., Dalton Trans., 1984, 1349.

8 V. A. Blatov, A. P. Shevchenko and D. M. Proserpio, Cryst. Growth Des., 2014, 14, 3576. See also: http://www.topos.samsu.ru/.

9 E. V. Alexandrov, V. A. Blatov, A. V. Kochetkov and D. M. Proserpio, CrystEngComm, 2011, 13, 3947.

10 PECJIS: (a) A. L. Pochodylo and R. L. LaDuca, Inorg. Chim. Acta, 2012, 389, 191; SUNHEP, SUNHIT, SUNHOZ: (b) J. Zhang, T. Wu, S. Chen, P. Feng and X. Bu, Angew. Chem., Int. Ed., 2009, 48, 3486; QUJHIN: (c) F. Guo, J. Coord. Chem., 2009, 62, 3621.

11 V. A. Blatov, L. Carlucci, G. Ciani and D. M. Proserpio, CrystEngComm, 2004, 6, 377.

12 L. Carlucci, G. Ciani and D. M. Proserpio, in Making crystals by design: methods, techniques and applications, ed. D. Braga and F. Grepioni, Wiley-VCH, Weinheim, 2007, ch. 1.3, p. 58.

13 O. Delgado-Friedrichs and M. O'Keeffe, J. Solid State Chem., 2005, 178, 2480.

14 X.-J. Ke, D.-S. Li and Du Miao, Inorg. Chem. Commun., 2001, 14, 788.

15 See for examples: (a) M. J. Plater, M. R. S. J. Foreman, T. Gelbrich and M. B. Hursthouse, J. Chem. Soc., Dalton Trans., 2000, 1995; (b) L.-P. Zhang, J. Yang, J.-F. Ma, Z.-F. Jia, Y.-P. Xie and G.-H. Wei, CrystEngComm, 2008, 10, 1410; (c) Y.-Y. Liu, Z.-H. Wang, J. Yang, B. Liu, Y.-Y. Liu and J.-F. Ma, CrystEngComm, 2011, 13, 3811; (d) Y.-Y. Liu, H.-Y. Liu, J.-F. Ma, Y. Yang and J. Yang, CrystEngComm, 2013, 15, 1897; (e) Y. Gong, P. G. Jiang, J. Li, T. Wu and J. H. Lin, Cryst. Growth Des., 2013, 13, 1059; $(f)$ D.-R. Xiao, Y.-G. Li, E.-B. Wang, L.-L. Fan, H.-Y. An, Z.-M. Su and L. Xu, Inorg. Chem., 2007, 46, 4158; $(g)$ R. Custelcean and M. G. Gorbunova, CrystEngComm, 2005, 7, 297; (h) K. Zhou, F.-L. Jiang, L. Chen, M.-Y. Wu, S.-Q. Zhang, J. Ma and M.-C. Hong, Chem. Commun., 2012, 5521; (i) G. O. Lloyd, 
J. L. Atwood and L. J. Barbour, Chem. Commun., 2005, 1845; (j) J.-K. Sun, Q.-X. Yao, Z.-F. Ju and J. Zhang, CrystEngComm, 2010, 12, 1709; (k) C.-C. Wang, S.-M. Tseng, S.-Y. Lin, F.-C. Liu, S.-C. Dai, G.-H. Lee, W.-J. Shih and H.-S. Sheu, Cryst. Growth Des., 2007, 7, 1783.

16 (a) P. Cromwell, Knots and Links, Cambridge University Press, England, 2004; (b) T. Castle, M. E. Evans and S. T. Hyde, Prog. Theor. Phys. Supp., 2011, 191, 235.

17 R. S. Forgan, J.-P. Sauvage and J. F. Stoddart, Chem. Rev., 2011, 111, 5434.

18 (a) T. Castle, M. E. Evans and S. T. Hyde, New J. Chem., 2008, 32, 1484; (b) T. Castle, Entangled graphs on surfaces in space, Ph.D. Thesis, Australian National University, Canberra, 2013, http://hdl.handle.net/1885/11978.

19 F. Li, J. K. Clegg, L. F. Lindoy, R. B. Macquart and G. V. Meehan, Nat. Commun., 2011, 2, 205.

20 X.-L. Wang, F.-F. Sui, H.-Y. Lin, C. Xu, G.-C. Liu, J.-W. Zhang and A.-X. Tian, CrystEngComm, 2013, 15, 7274.

21 (a) G.-P. Yang, J.-H. Zhou, Y.-Y. Wang, P. Liu, C.-C. Shi, A.-Y. Fu and Q.-Z. Shi, CrystEngComm, 2011, 13, 33; (b) G.-P. Yang, Y.-Y. Wang, P. Liu, A.-Y. Fu, Y.-N. Zhang, J.-C. Jin and Q.-Z. Shi, Cryst. Growth Des., 2010, 10, 1443; (c) T. Liu, J. Lu, L. Shi, Z. Guo and R. Cao, CrystEngComm, 2009, 11, 583.

22 A. L. Spek, J. Appl. Crystallogr., 2003, 36, 7. 